\title{
The potential of fog harvesting in tropical highlands as an alternative water resource: the case of Atok, Benguet, Philippines
}

\author{
Fibor J. Tan ${ }^{1, *}$ Maria Angelica P. Estanislao ${ }^{1}$, Angelica Mhae A. Gregorio ${ }^{1}$, and Ivan Jeff D. Navea ${ }^{1}$ \\ ${ }^{1}$ School of Civil, Environmental, \& Geological Engineering, Mapúa University, Muralla St., Intramuros, Manila 1002, Philippines
}

\begin{abstract}
One of the sources of freshwater is groundwater, from below the ground. However, due to excessive human consumption and population growth, groundwater depletion has been a pressing problem all over the world, and it can lead to water scarcity in the future. In elevated areas where water scarcity is rampant due to its high elevation thus resulting in seasonal low surface and groundwater flow, the use of alternative water resources must be assessed. One of the alternative water resources is fog collectors which involves the use of fog harvesting technology. This paper aims to study the application of fog catchers in Atok, Benguet, Philippines by analyzing the fog water collected from standard fog catchers for one month. To determine the suitable fog catcher materials in the area, two types of mesh materials (Raschel mesh and Polypropylene) were installed and analyzed for their water collection ability, availability in the area, and strength to withstand environmental factors. An average of 0.30036 liter/meter/day and 0.20695 liter/meter/day of water were collected from the Raschel mesh and Polypropylene mesh, respectively. The results of this study can pave the way for further development and assessment of the application of fog catchers in the Philippines as an alternative water resource in elevated areas to provide solution to water scarcity.
\end{abstract}

\section{Introduction}

Freshwater is a renewable but finite resource that is considered one of the most essential elements for human survival. Human water use today exceeds sustainable levels, which results in groundwater depletion and low or nonexistent surface water flow. These effects will result in water scarcity in the future [1].

One area in the Philippines that relies heavily on groundwater and experiences the consequences of water scarcity is Atok, Benguet, specifically the town of Upper Englandad, due to its high elevation. According to the census conducted by the Philippine Statistical Authority there is a continuous increase in the population of Benguet, with a 1.99 population growth rate from years 2000 to 2015. Due to the continuous increase in population in the area resulting in further depletion of groundwater supply, it can be predicted that the gap experience between the water supply and demand will further increase in time. With this problem, an additional alternative water resource can help the area supply the needed gap in its water demand.

Fog has the potential of supplying water to areas where fog formation is a normal occurrence. The technique of collecting water vapor from fog through the use of fog catchers is called fog harvesting which is an alternative method that has been devised in South America in the 1900s [2]. In arid places where water scarcity is rampant such as Peru, Chile, Ghana, and Eritrea, fog catchers are utilized as a water resource. Fog water harvesting is not limited to arid places, but it also has potential application to highland tropical areas such as some parts of Mexico and the Philippines [3].

According to PAGASA data last 2017, the average fog formation in Benguet is 30 days per month. With the water scarcity and the data of fog formation in the area, Atok, Benguet is an ideal place for the installation of fog catchers in the Philippines.

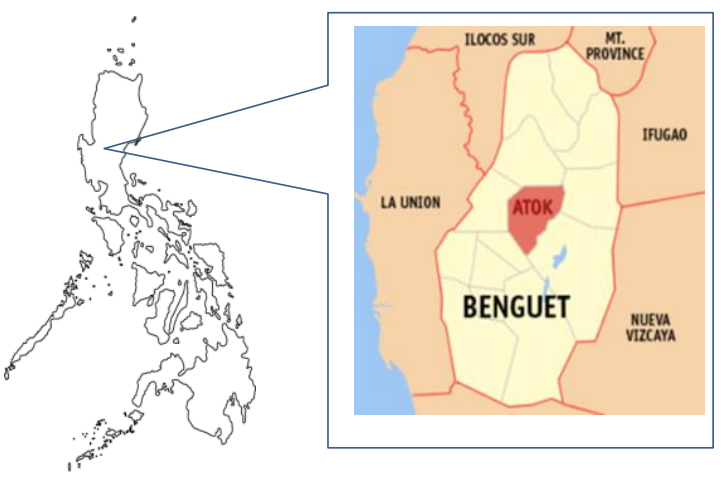

Figure 1. Geographical Map of Atok, Benguet 
In this study, two materials, Raschel mesh and Polyethylene Mesh, were tested for their water collection effectivity. The Raschel mesh is the typical mesh used in previous studies which utilizes fog water as a water resource while the Polyethylene Mesh is the proposed mesh material specifically for Atok, Benguet. Based on the results from previous studies, the use of Raschel mesh for fog catcher presents a huge problem when it comes to its sustainability for it is frequently damaged by strong winds events and other environmental factors [4]. Therefore, a Polypropylene Mesh with greater elastic capacity and is readily available in local stores in Atok, Benguet is proposed for this study since the Philippines is frequented by tropical cyclones.

The main objective of this research was to assess the potential of fog harvesting thru the application of fog catchers in Atok, Benguet, Philippines. Specifically the research addressed the following:

1. Determine the feasibility of fog catchers in Atok, Benguet by analyzing and comparing its atmospheric characteristic from previous studies.

2. Create a fog collector prototype to determine the volume of water that can be collected in the area.

3. Assess an alternative material for fog catcher and compare its water collection efficiency to the conventional fog catcher design.

4. Determine a fog catcher design that can serve as an additional water resource using data from the standard fog catcher prototype.

The study analyzed the atmospheric and topographical characteristics of the specified area and determined its feasibility for fog harvesting. The characteristics that were analyzed are: wind direction, relative humidity, elevation, and water resources in Atok, Benguet. The study is focused on the application of fog catchers in Atok, Benguet using data gathered from the created standard fog collector prototype for one month. The water that will be harvested from the fog catchers can serve as a potential alternative water resource for the beneficiaries as a solution to their problem of water deficiency. In addition, this study compared the results of Raschel mesh and the proposed Polypropylene Mesh, taking in consideration its water collecting ability, strength, cost, and availability.

\section{Methodology}

To determine the site characteristics of Atok, Benguet, the researchers requested and obtained data from Philippine Atmospheric, Geophysical, and Astronomical Services Administration (PAGASA). The data from PAGASA includes the information related to the weather: wind direction, wind speed, relative humidity, fog formation, and annual precipitation. Climatological normal data from the year 1981 to 2017 have been used for this study for accurate results taking in consideration the variability of weather variables for each year.

The study site is the high grounds of Cattubo, Atok, in the province of Benguet which is three hours from the City of Baguio. The municipality is characterized as hilly to mountainous with a third of its areas as slopes. The elevated areas are characterized as rugged mountains with increasing altitudes to the east and west. The site where the two fog catchers where installed are 2400 meters above the ground which nears the peak of the mountains. As the study site is near the peak of the mountains, the air that flows over the rising terrain develops into upslope fog which provides regular fog events in the area. After determining the site characteristics of Atok, Benguet, and the researchers analyzed the gathered data by comparing them to previous studies as a standard in determining its feasibility to host fog catchers. Areas with fog and light winds are the sites with the highest potential for the development of fog harvesting techniques [5]. Wind velocities between $2 \mathrm{~m} / \mathrm{s}$ and $7.5 \mathrm{~m} / \mathrm{s}$ generate higher amounts of fog water collection. The relative humidity of $90 \%$ to $100 \%$ also generates high amounts of fog water collection, although the value of humidity does not define the feasibility of fog catcher but rather depends on the occurrence of fog and light winds. When the feasibility of the site was deemed to be potential for fog harvesting, the study will proceed to the creation of standard for catcher [6].

To determine the potential volume of water that can be collected in a given location, a 1 meter by 1 meter standard fog collector was established in the area. For this study, two types of standard fog collectors were installed to determine the suitable mesh material for the given site considering the water collection efficiency of the mesh and its availability in the area.In this study, Polypropylene mesh and Raschel mesh were both used. The first type of mesh was the proposed alternative mesh that is readily available in the area, while the second type of mesh was the conventional mesh used in previous studies.

For the design of the fog catchers, a 1 meter by 1 meter Raschel mesh and Polypropylene mesh was used to determine the water collection rate in the study area. To eliminate the discrepancies of the results, the two SFCs where placed $0.75 \mathrm{~m}$ from each other, making sure they have the same elevation and both have a clear path from the wind. For the optimization of mesh area, the fog catcher should be mounted perpendicular to the wind direction. From the climatological normal data of PAGASA, the wind direction for the duration of this study comes from southeast (SE) of the country. Therefore, the SFCs were oriented facing the SE direction [23].

The mesh is supported by structural angle bar steel frames for sustainability and strength against wind. The option of using wood was not entertained due to the high humidity in the area that can cause the wood to swell up and eliminate the sustainability approach of the project. For standardization, the SFCs were mounted 2 meters from the ground to maximize the exposure to the wind [6]. The poles were also buried 1 meter below the ground for stability and are secured by tension cables to withstand wind loads during typhoon [7].

For the collection of water from the mesh, a PVC was cut in half and served as a catchment basin for the water. A hose was connected to the PVC to direct the water collected to a plastic container which is sealed to prevent the evaporation for accurate results.

In this study, the water collected by the fog catcher prototypes were measured daily by the help of a local hire. A five-gallon plastic container was used as storage for the 
water collected. To measure the water collected by the fog catcher per day, the plastic container had labels with an increment of $1 \mathrm{~cm}$; the volume was then computed by using the dimensions of the container. To determine the approximate time of fog occurrence in the area that contributed to the water collection, the local help recorded two measurements, at 6 am and $6 \mathrm{pm}$. The water collected from the two prototypes was then analyzed and their significant difference was compared. The average water collected by each type of the prototype was also compared to the water collected by previous studies to determine its significance to other studies.

\section{Results and Discussions}

\section{Climatological Normals}

To determine the feasibility of the site to host a fog harvesting system, certain parameters were analyzed in comparison to previous studies. These parameters are: elevation, wind speed, temperature, and relative humidity. For this study, the climatological normals of Baguio City were used as a basis for the determination of the feasibility of Atok, Benguet to catch water from fog. This is because there is only one weather station of PAGASA in Benguet which is situated in Baguio City. Figures 2 and 3 are graphical representations of the site's climatological data.

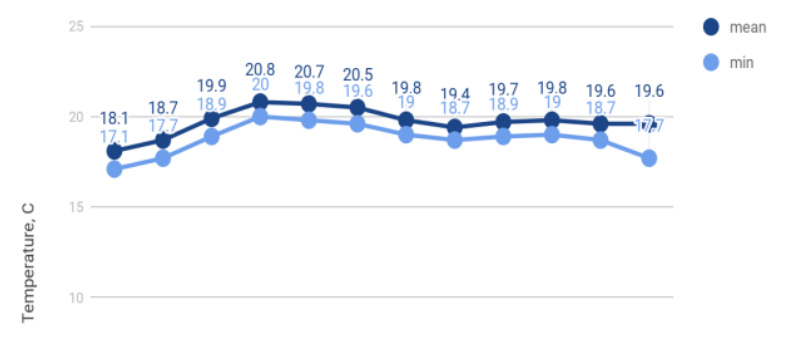

JAN FEB MAR APR MAY JUN JULY AUG SEP OCT NOV DEC

Figure 2. Graph of Mean and Minimum Temperatures of Baguio City according to Climatological Normals as of 2017.

As shown in the difference in the mean temperature and the minimum temperature line graph, it can be concluded that for Baguio City, the temperature is constantly low, which can be correlated to high relative humidity. This indicates that the area has a potential for events of daily fog occurrence.

High events of fog collection were observed when the relative humidity was between the ranges from $90 \%$ to $100 \%$ [6]. From the graph of relative humidity shown according to the climatological normals of Baguio City as of 2017 , the area's relative humidity had an average of $84 \%$ to $89 \%$ relative humidity, which does not reach the required percentage according to the previous study.

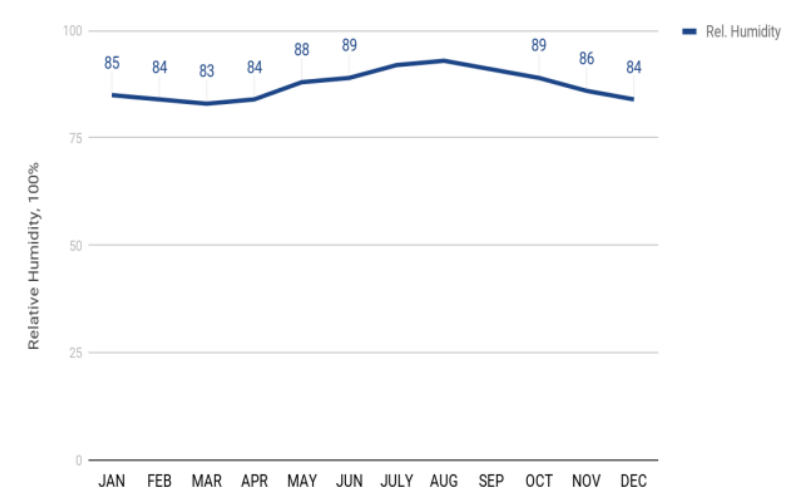

Figure 3. Graph of Relative Humidity of Baguio City according to Climatological Normals as of 2017.

Since the study location is situated 3 hours away and has a difference in elevation of almost 900 meters from Baguio City, it can be concluded that at Atok, Benguet, the higher of the two locations, has a lower ambient temperature than Baguio City [8]. This lower temperature results into higher relative humidity for Atok since relative humidity is inversely proportional to the air temperature [9]. Since the weather station for the whole province of Benguet is in Baguio City, the climatological normals of Baguio City was used to determine the feasibility of fog harvesting in Atok, Benguet. Areas with average wind velocity of $2 \mathrm{~m} / \mathrm{s}$ to $7.5 \mathrm{~m} / \mathrm{s}$, exhibit higher amounts of water collection events. Fog develops when areas experience light winds. The study area has an average wind speed of $2 \mathrm{~m} / \mathrm{s}$ the whole year round. This value indicates that the study area has the potential to develop fog events throughout the year. This average wind velocity does not consider the events where typhoon is involved [10] [6].

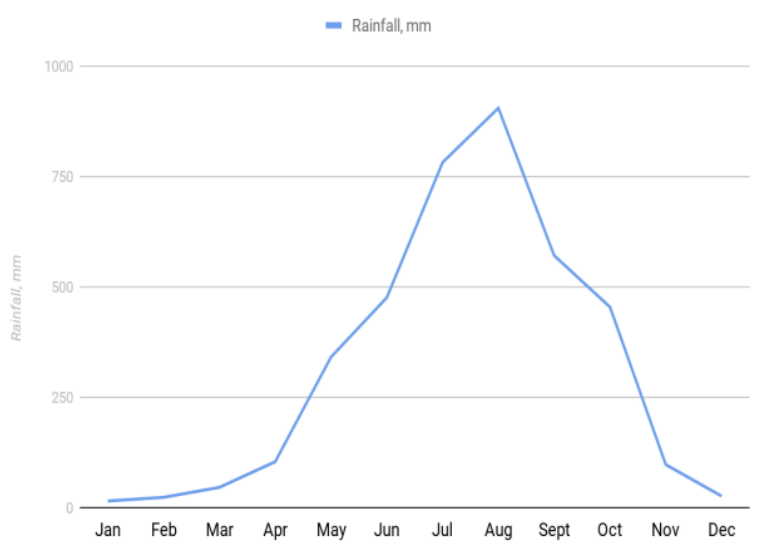

Figure 4. Graph of Average Rainfall in Millimeters of Baguio City according to Climatological Normals as of 2017.

From the data in Figure 4, it can be seen that for half of the year, the area experienced high precipitation. Atok, Benguet, as one of the municipality with the highest elevation in the country experience water scarcity during dry months. Therefore, the water collection from fog catchers is applicable to the study site during the dry season [3]. 


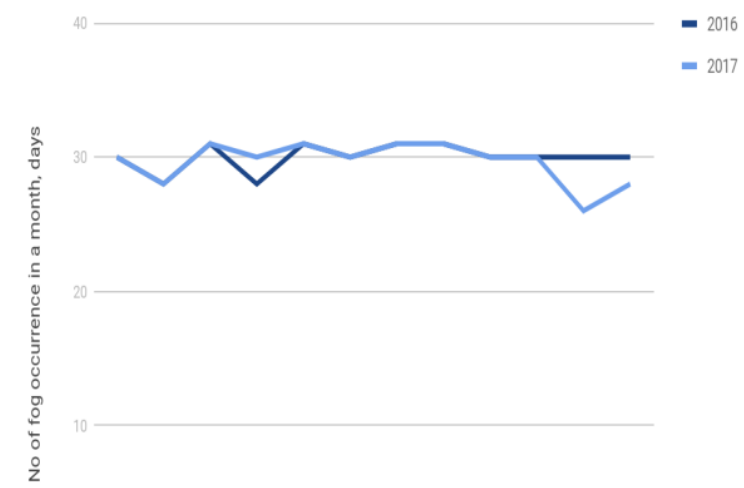

JAN FEB MAR APR MAY JUN JULY AUG SEP OCT NOV DEC

Figure 5. Graph of Number of Days where Fog Occurrence is Observed in Baguio City According to Climate and Agromet Data during 2016 and 2017.

From the data on the climate and agromet of Baguio City from PAGASA for 2016 and 2017, it can be seen that the area experienced fog for an average of 30 days per month. This data further supports the inference of the researchers that Baguio City experienced regular fog occurrence throughout the year. Figure 5 shows a virtual representation of the number of days a fog event was observed in the area. Because Atok, Benguet, has climatological characteristics like Baguio, it can be concluded that the area also experiences the same average fog occurrence per month.

\section{Comparison of two Standard Fog Collector Prototypes}

For this study, two types of fog catchers having the same mesh area of 1 square meter were installed in Atok, Benguet for the analysis and comparison of their water collection efficiency. One type of fog catcher installed was a standard fog collector made with Raschel mesh while the other type was the proposed alternative design fog catcher made with a Polypropylene Mesh as shown in Figure 5. The prototypes were placed near each other to eliminate differences in parameters such as wind speed, wind direction and elevation that can contribute to the difference of their water collection efficiency.

Table 1. Tabulated Parameters of the Shade Coefficient of the two meshes

\begin{tabular}{|c|c|c|}
\hline & Raschel Mesh & Polypropylene Mesh \\
\hline $\begin{array}{c}\text { Radius of the Mesh } \\
\text { Fiber }\end{array}$ & $0.5 \mathrm{~mm}$ & $0.5 \mathrm{~mm}$ \\
\hline $\begin{array}{c}\text { Half of the spacing } \\
\text { Shade Coefficient }\end{array}$ & $4 \mathrm{~mm} \%$ & $4 \mathrm{~mm}$ \\
\hline
\end{tabular}

The shade coefficient of the mesh is one of the factors that enables the fog catcher capture the fog in the atmosphere. Based on the gathered data, the shade coefficient of the two mesh shall be neglected since it has the same value of shade coefficient.

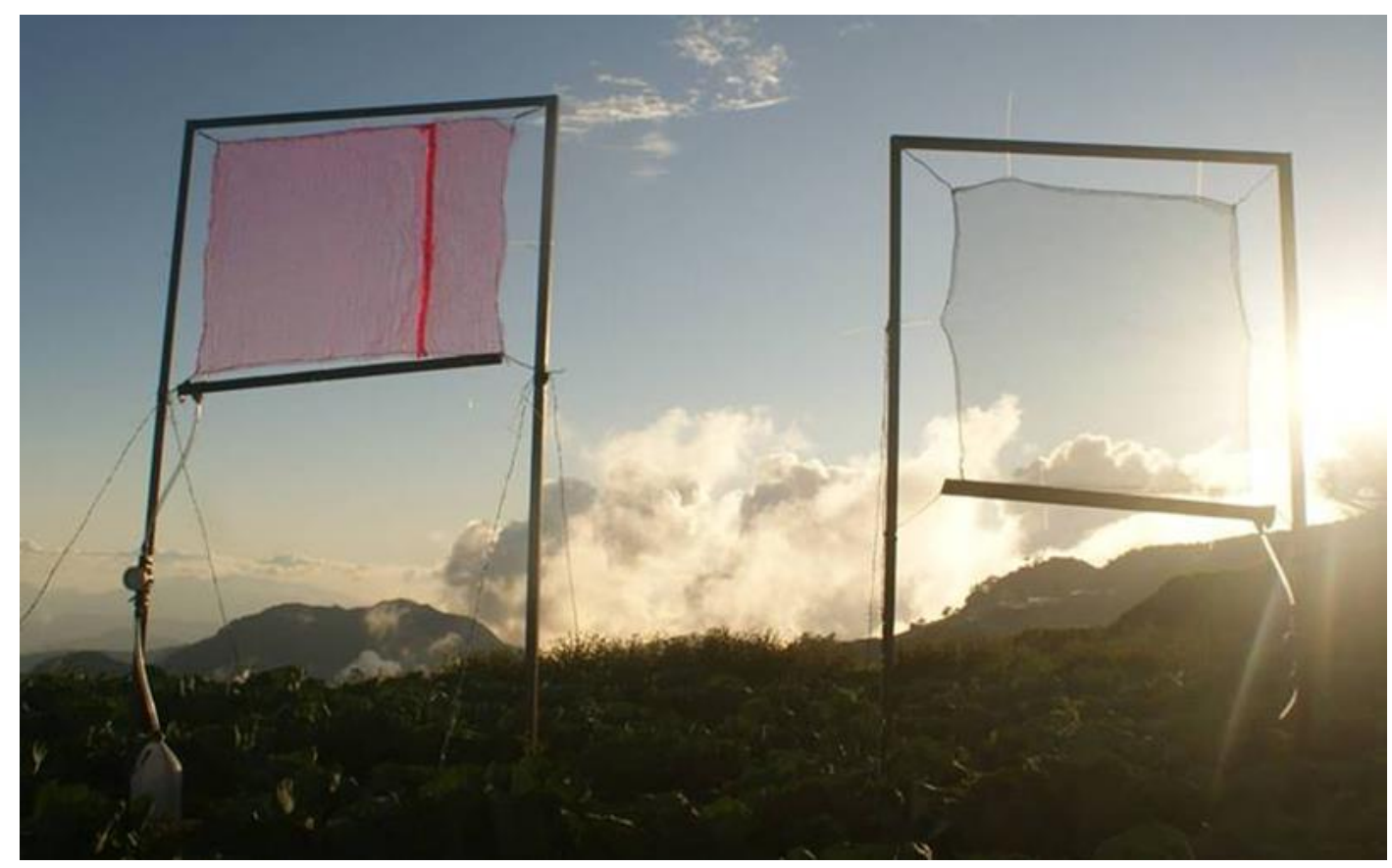

Figure 6. Side by Side Comparison of Fog Collectors. Raschel mesh (left) and Polypropylene mesh (right).

The amount of water accumulated from the fog collectors was determined using the increment of water in the container. Given the dimensions of the container, the volume of water collected was then computed. Two readings were done in a day, at 6:00 a.m. and 6:00 p.m. From December 10, 2018 to December 18, 2018, the following data were gathered by the fog collectors. Table 2 shows the volume of water collected by the fog catchers. 
Table 2. Volume of water collected by the fog collectors (Liters $/ \mathrm{m}^{2} /$ day)

\begin{tabular}{|c|c|c|c|c|c|c|}
\hline \multirow[t]{2}{*}{ Date } & \multicolumn{2}{|c|}{ A (Raschel) } & \multirow{2}{*}{$\begin{array}{l}\text { Volume of water } \\
\text { collected } \\
\left(\mathrm{L} / \mathrm{m}^{\prime} \text { Day }\right)\end{array}$} & \multicolumn{2}{|c|}{ B (Polypropylene) } & \multirow{2}{*}{$\begin{array}{l}\text { Vol. of water } \\
\text { collected } \\
\text { (L/m²/Day) }\end{array}$} \\
\hline & Morning (6AM) & Evening (6PM) & & Morning (6AM) & Evening (6PM) & \\
\hline $12-10-2018$ & $0.5674 \mathrm{~L}$ & $0.5674 \mathrm{~L}$ & 0.5674 & $0.5674 \mathrm{~L}$ & $0.5674 \mathrm{~L}$ & 0.5674 \\
\hline 12-11-2018 & $0.6810 \mathrm{~L}$ & $0.6810 \mathrm{~L}$ & 0.1136 & $0.6810 \mathrm{~L}$ & $0.6810 \mathrm{~L}$ & 0.1134 \\
\hline $12-12-2018$ & $0.6810 \mathrm{~L}$ & $0.6810 \mathrm{~L}$ & 0 & $0.6810 \mathrm{~L}$ & $0.6810 \mathrm{~L}$ & 0 \\
\hline $12-13-2018$ & $0.6810 \mathrm{~L}$ & $0.6810 \mathrm{~L}$ & 0 & $0.6810 \mathrm{~L}$ & $0.6810 \mathrm{~L}$ & 0 \\
\hline $12-14-2018$ & $0.7944 \mathrm{~L}$ & $0.7944 \mathrm{~L}$ & 0.1134 & $0.6810 \mathrm{~L}$ & $0.6810 \mathrm{~L}$ & 0 \\
\hline $12-15-2018$ & $0.9080 \mathrm{~L}$ & $0.9080 \mathrm{~L}$ & 0.1136 & $0.7944 \mathrm{~L}$ & $0.7944 \mathrm{~L}$ & 0.1134 \\
\hline $12-16-2018$ & $0.9080 \mathrm{~L}$ & $0.9080 \mathrm{~L}$ & 0 & $0.7944 \mathrm{~L}$ & $0.7944 \mathrm{~L}$ & 0 \\
\hline $12-17-2018$ & $0.9080 \mathrm{~L}$ & $0.9080 \mathrm{~L}$ & 0 & $0.7944 \mathrm{~L}$ & $0.7944 \mathrm{~L}$ & 0 \\
\hline $12-18-2018$ & $0.9080 \mathrm{~L}$ & $0.9080 \mathrm{~L}$ & 0 & $0.7944 \mathrm{~L}$ & $0.7944 \mathrm{~L}$ & 0 \\
\hline $12-19-2018$ & $1.0214 \mathrm{~L}$ & $1.0214 \mathrm{~L}$ & 0.1134 & $0.7944 \mathrm{~L}$ & $0.7944 \mathrm{~L}$ & 0 \\
\hline $12-20-2018$ & $1.0214 \mathrm{~L}$ & $1.0214 \mathrm{~L}$ & 0 & $0.7944 \mathrm{~L}$ & $0.7944 \mathrm{~L}$ & 0 \\
\hline $12-21-2018^{*}$ & $1.0214 \mathrm{~L}$ & $2.6102 \mathrm{~L}$ & 0 & $0.7944 \mathrm{~L}$ & $1.9293 \mathrm{~L}$ & 0 \\
\hline $12-22-2018$ & $2.6102 \mathrm{~L}$ & $3.1777 \mathrm{~L}$ & 1.5888 & $1.9293 \mathrm{~L}$ & $2.1563 \mathrm{~L}$ & 1.1349 \\
\hline $12-23-2018^{*}$ & $3.1777 \mathrm{~L}$ & $3.5182 \mathrm{~L}$ & 0.5675 & $2.2698 \mathrm{~L}$ & $2.3832 \mathrm{~L}$ & 0.3405 \\
\hline $12-24-2018$ & $4.6531 \mathrm{~L}$ & $4.8800 \mathrm{~L}$ & 1.4754 & $3.4047 \mathrm{~L}$ & $3.5182 \mathrm{~L}$ & 1.1349 \\
\hline $12-25-2018$ & $4.9937 \mathrm{~L}$ & $5.1071 \mathrm{~L}$ & 0.3406 & $3.5182 \mathrm{~L}$ & $3.5182 \mathrm{~L}$ & 0.1135 \\
\hline $12-26-2018$ & $5.1071 \mathrm{~L}$ & $5.1071 \mathrm{~L}$ & 0.1134 & $3.5182 \mathrm{~L}$ & $3.5182 \mathrm{~L}$ & 0 \\
\hline
\end{tabular}

On day 18 of the installation, the conventional (the Raschel mesh) standard fog collector was damaged due to heavy rainfall and strong winds. Figure 11 shows the damaged conventional (the Raschel mesh) fog catcher. Based on this occurrence, it can be observed that the Polypropylene Mesh has greater durability than the Raschel Mesh. In relation to the analysis, a study by O'Hara (2007) reported that the woven mesh which is Polypropylene Mesh has greater strength and elasticity than the knitted mesh (Raschel Mesh) which was proven by this event [9].

\section{Comparison of Standard Fog Collector to other related studies}

A comparison between the water collected rate from the standard fog collectors and the standard fog collector from previous studies was done to determine the feasibility of the proposed fog catcher in the Philippines. A summary of the average amount of water collected rate in various parts of the world, as reported in previous studies, is shown in Table 3.

The water collected rate from previous studies ranged from $0.1 \mathrm{Lm}^{-2} \mathrm{day}^{-1}$ to $25 \mathrm{Lm}^{-2} \mathrm{day}^{-1}$ while the fog collector of this study ranged from $0.2 \mathrm{Lm}^{-2} \mathrm{day}^{-1}$ to $0.3 \mathrm{Lm}^{-2} \mathrm{day}^{-1}$. Based on the gathered data, the water collected from the fog collector is feasible.
Table 3. Summary of the Average Fog Water Collected Rate Reported from Previous Studies

\begin{tabular}{|c|c|}
\hline Project Location & $\begin{array}{c}\text { Rate of fog water } \\
\text { collected } \mathbf{L} / \mathbf{m}^{2} / \mathbf{d a y}\end{array}$ \\
\hline Cerro Orara, Peru & $9-25$ \\
\hline Cerro Moreno, Chile & 8.26 \\
\hline Alto Patache, Chile & 7.21 \\
\hline Arborobu, Eritrea & 7.9 \\
\hline Salagna Plateau, Haiti & 5.5 \\
\hline Toquia, Guatemala & 4 \\
\hline Embatkala, Eritrea & 3.6 \\
\hline El Tofo, Chile & 2.98 \\
\hline Dominican Republic & 2.5 \\
\hline Collanac, Peru & $2-5$ \\
\hline Falda Verde, Chile & 1.43 \\
\hline Namibia & $0.1-1.1$ \\
\hline Cerro Guatalaya, Chile & 0.93 \\
\hline
\end{tabular}




\section{Conclusions}

This chapter concludes the whole study, addressing the objectives based on the analyzed results. The application of fog catcher in Atok, Benguet enabled the determination of collection of water using fog harvesting techniques in the given site. This study can pave the way for the use of fog catcher as an alternative water resource in mountainous remote areas where water scarcity is a problem due to high elevation. The water collected from the fog catchers can be utilized as an alternative source of water for food preparation, washing of clothes, and other domestic uses. According to the topographical and climate data of Atok, Benguet as of the year 2017, the area experiences regular fog occurrence which makes it feasible for the installation of fog catchers.

The researchers installed two types of mesh and compared them to each other, taking in consideration the cost, water collection ability and their strength against environmental factors such as wind. The conventional mesh had a rate of $0.30036 \mathrm{~L} / \mathrm{m}^{2}$ per day while the proposed mesh had a rate of $0.20695 \mathrm{~L} / \mathrm{m}^{2}$ per day. From the analyzed results, it can be concluded that there was no significant difference in the volume collected by the conventional knitted (Raschel) mesh and the proposed (Polypropylene) woven mesh when all parameters for fog collection ability were the same. With regard to the strength of the meshes, one important finding is that the conventional mesh was damaged due to heavy rainfall and strong winds and was rendered as non-operational for half of the study. Because the site location is remote, a design using sustainable materials is preferred.

The researchers compared the water collection rate of the standard fog catchers to the water collection rates of previous studies. The rate of the previous studies ranges from 0.1 $25 \mathrm{Lm}^{-2} \mathrm{day}^{2}$. Comparing the values of fog water collection rate of this study to previous studies, the result of this study is between the range of previous studies, thus concluding the study as successful and significant compared to previous studies. Also, the researchers concluded that the application of fog catcher in Atok, Benguet is feasible.

To fully determine the application of fog catcher in Atok, Benguet, a longer study period must be taken into consideration to determine the water collection ability of the fog catchers for the two-season climate of the Philippines. Therefore, the researchers recommend at least a full year of gathered data to determine its application. The researchers also recommend taking consideration of installing fog catchers in different locations of a certain site to determine the optimal location for fog harvesting and to create a rain measuring tool on site to determine the measurement of rain during days where fog and precipitation occurs.

To optimize the fog collection in Atok, Benguet, the researchers recommend the assessment of different mesh materials, taking into consideration its strength to withstand environmental factors such as strong winds and heavy rains and its water collecting ability. A mesh which has a higher water collecting ability and high durability compared to the conventional fog catcher must be researched and tested out on site in future studies.

\section{Reference}

1. S. L. Postel. Entering an Era of Water Scarcity: The Challenges Ahead.Ecological Applications, 10(4), 941.doi:10.2307/2641009 (2000).

2. J. Prisco. 'Fog catchers' make water out of thin air.RetrievedFromhttps://edition.cnn.com/2016/11/18/af rica/fog-catchers

morocco/index.html?fbclid=IwAR3eoRzrPM5yKDxra7 ieBN_8JNAS20BJTNByB6FgN7kumXAWRm4lnsYZo bo (2016).

3. T. Hess. Fogwater Harvesting for Community Water Supply. Retrieved from https://sswm.info/ (1998).

4. R. S. Schemenauer. Fog water collection manual.FogQuest: SustainWater Solutions. Retrieved fromhttps://www.researchgate.net/publication/28336455 9_Fog_water_collectio_manual (2005).

5. S. C. Montecinos. Collection efficiency of fog events. Atmospheric Research, 209,163-169. doi:10.1016/j.atmosres.2018.04.004 (2018).

6. P. Gandhidasan, \& H. I. Abualhamayel. Exploring Fog Water HarvestingPotentialand Quality in the Asir Region, Kingdom of Saudi Arabia.Pure and Applied Geophysics.169(5-6), 1019-1036. doi:10.1007/s00024011-0341-z (2011)

7. R. S. Schemenauer. A Proposed Standard Fog Collector for Use in High-ElevationRegions. Journal of Applied Meteorology, 33(11), 1313-1322. doi:10.1175/15200450(1994)0332.0.co;2 (1993).

8. H.F. Diaz, M. Grosjean, L. Graumlich. Climate Variability and Change in HighElevation Regions: Past, Present and Future. Advances in Global Change ResearchClimate Variability and Change in High Elevation Regions: Past, Present \& Future, 14.doi:10.1007/978-94-015-1252-7_1 (2003)

9. B. F. O Hara. Weather and climate of the Reno-Carson City-Lake Tahoe Region. Reno, NV: Mackay School of Earth Sciences and Engineering, University of Nevada, Reno. (2007).

10. C. M. Regalado. The performance of three fog gauges under field conditions and its relationship with meteorological variables in an exposed site in Tenerife (Canary Islands). Agricultural and Forest Meteorology, 233, 80-91.

doi:https://doi.org/10.1016/j.agrformet.2016.11.009 (2017). 